\title{
Black economic empowerment in the EASTern CaPe Automotive Industry: CHALlenges AND POLICIES
}

\author{
Gideon S Horn
}

Department of Logistics Management, Nelson Mandela Metropolitan University

\begin{abstract}
Original Equipment Manufacturers (OEMs) in South Africa are under pressure to meet the Black Economic Empowerment (BEE) policies and charters of the South African government by giving BEE suppliers additional opportunities to tender. However, many BEE suppliers, due to being historically disadvantaged, experience various problems which make it difficult for them to win tenders, including lack of finances, opportunities to tender and management and business skills, and problems with quality and capacity. This paper outlines these practical problems experienced by BEE suppliers, the effects of these problems on risk and complexity in the South African automotive industry and policies that address these problems and assist BEE suppliers to become A-rated suppliers. Data for the paper was obtained from interviews with: senior employees of the AIDC involved with supplier development training; middle managers of supplier quality and development departments at the three OEMs in the Eastern Cape Province; and BEE and small suppliers identified to undergo AIDC training. The findings of the study are that unless sufficient training is given to BEE and potential BEE suppliers, supply to OEMs will remain in the hands of existing established suppliers and very little transformation will occur within the automobile industry in South Africa.
\end{abstract}

JEL J70, L62

\section{1}

\section{Introduction}

The performance of the South African automotive industry and its contribution to the country's economic growth in recent years has been significant. The automotive industry's economic achievements include the following (Automotive Industry Development Centre, 2005: 7, 11; National Association of Automobile Manufacturers of South Africa, 2007):

- A contribution of 6.6 per cent towards South Africa's gross domestic product (GDP);

- Becoming the third largest sector in the economy after mining and financial services, accounting for 30.0 per cent of the country's manufacturing output;

- The employment of approximately 297000 people directly, and of many more as an indirect result of the sector's growth;
- As the twentieth largest manufacturer of vehicles in the world, integration into the global framework of parent companies and multinationals;

- An increase in the export of fully built-up vehicles from 139912 in 2005 to 179859 in 2006 (an increase of 28.6 per cent), generating a significant amount of foreign exchange, in spite of growing competition from imports and worsening international conditions.

The success of the South African automotive industry has resulted in it becoming a benchmark for the other prioritised sectors in the country. However, the industry is now challenged to maintain and improve on its successes. In addition, the South African government's general policies and charters with regard to black economic empowerment (BEE), equity and redress make this challenge even more 
daunting. The reason for this is that in terms of these BEE policies, pressure is put on large and financially strong enterprises, including original equipment manufacturers (OEMs), also referred to as motor vehicle assemblers, to procure to a greater extent from BEE or previously disadvantaged suppliers (Hugo, Badenhorst-Weiss \& Van Biljon, 2004: 53). These suppliers, however, tend to experience various problems and do not always meet the stringent standards demanded by OEMs. These problems, which will be discussed in the findings of this article, need to be addressed, and the role played by BEE suppliers closely monitored and encouraged if they are to make a greater contribution to the country' economic development and the economic empowerment of previously disadvantaged groups.

The objectives of this article are therefore to outline:

- practical problems experienced by BEE and small suppliers in the Eastern Cape automotive supply chain;

- the possible effects of these problems on risk and complexity in the South African automotive supply chain;

- policies and procedures currently in place to assist BEE and small suppliers in the South African automotive industry to secure more contracts; and

- challenges faced by higher education and other training institutions in their efforts to develop the required human resource capacity among BEE suppliers.

\section{2}

\section{Background notes on the Eastern Cape automotive industry}

The South African automotive industry is concentrated in three regions in the country (Automotive Industry Development Centre, 2005: 13). The most important region is the Gauteng Province, which is home to four OEMs (BMW, Nissan, Fiat and Ford), and represents approximately 50 per cent of the country's automotive components industry. The second most important region is the Eastern
Cape Province, which is home to three OEMs as well as almost 30 per cent of the country's automotive components industry. The three OEMs situated in this region are General Motors in Port Elizabeth, Volkswagen in Uitenhage and DaimlerChrysler in East London. Port Elizabeth also houses the Ford engine plant which is a major manufacturer and exporter of motorcar engines. The third major region is Durban/ Pietermaritzburg, which has one OEM (Toyota), and represents approximately 15 per cent of the country's components industry.

Although the Eastern Cape is the second most important automotive region in South Africa, it is regarded as one of the country's poorest provinces in terms of both the Human Development Index (HDI) and the Provincial Poverty Rate (PPR) (May, 2005). As economic development and BEE challenges are acute in this province, a theoretical and empirical study was undertaken to determine the main practical problems experienced by BEE suppliers in the Eastern Cape automotive industry.

\section{3}

\section{Research methodology}

This article is based on research that combined a literature review and an empirical study. The aim of the empirical study was to identify the main problems experienced by BEE and small suppliers in the Eastern Cape automotive industry. This process formed part of a bigger study on the automotive industry, funded by the National Research Foundation (NRF), to determine the skill shortages of previously disadvantaged suppliers in the industry. Information was gathered by means of a structured questionnaire used to elicit information. The sample comprised selected participants who took part in the cluster training offered by the Automotive Industry Development Centre (AIDC), which is explained in the next paragraph.

In both the Eastern Cape and Gauteng Provinces where it has offices, the AIDC runs various training and other programmes for small firms in partnership with business, government departments and other organisations, especially higher education institutions, 
focusing on functional, interactive and leadership competencies in career areas such as manufacturing, logistics, finance and human resources. In the Eastern Cape Province specifically, the Eastern Cape AIDC has been very successful in running total production improvement programmes, focusing particularly on logistics and production processes. The programmes were developed by the United Nations Industrial Development Organisation (UNIDO) and the Confederation of Indian Industries (CII). These training programmes are funded mainly by the Department of Trade and Industry (DTI), with small additional contributions from the businesses undergoing the training. In the programmes, businesses are clustered into groups of five. These small clusters are first assessed in terms of the whole production spectrum, which includes procurement, logistics, warehousing, marketing, cost reduction, material flow and production planning, and specific problem areas identified. The clusters are then given training focussed on the identified problem areas. Once these supplier businesses reach the appropriate standards, their names are placed on bidders lists from which OEMs can source their supplies.

A sample size of 30 respondents was decided on and consisted of the following people:

- two senior employees of the AIDC who are involved in supplier development training;

- five middle managers of supplier quality and development departments at the three OEMs in the Eastern Cape Province; and

- $23 \mathrm{BEE}$ and small suppliers who were identified to undergo training.

Before the survey was conducted, the questionnaire was evaluated for non-ambiguity, relevance, transparency, general validity and interpretation. Interpretation refers to the respondents' feedback which indicates whether the questions were in line with what the researchers intended measuring. The results of this evaluation were used in determining the final format of the questionnaire, to make sure it was properly adapted for the specific objectives of the study. Because of the nature of the questionnaire, the Windows-based Statistical Package for the Social Sciences (SPSS) software package was used. This is a complete package that can be used to enter, analyse, graphically display and report information. This computer package also allows the user to capture open-ended questions as they appear on the questionnaire.

To minimise the measurement errors associated with a single survey of this nature and to verify the authenticity of the gathered information, as many cross-tabulations were run as possible. The data obtained in this study can therefore be considered reliable, as every precaution was taken to ensure that questions were clearly understood before the responses were recorded. The responses obtained are tabulated, interpreted and discussed in this article.

\section{4}

\section{Theoretical perspectives on problems faced by small suppliers}

Textbook theory states that any business whose main focus is satisfying customer needs should, if it aims to achieve maximum profit, obtain the highest possible return (output) with the lowest possible cost (input) of production resources (Hugo et al., 2006: 7). This involves procuring requirements of the right quality in the right quantities at the right time and price, from the right source, and with delivery at the right place (Vogt, Pienaar \& De Wit, 2005: 23). To achieve all these elements simultaneously is very difficult, indeed not always possible, so successful purchasing is often a compromise between these various criteria. For example, if a particular component is needed right away, the urgency of the need overrides the best price as the most important factor in supplier selection. In all cases, however, selecting the wrong supplier is costly. It can weaken a business's competitive position, causing stock to run out, interruptions in production, the payment of unnecessarily high prices for supplies, consequent higher production costs and lower profits or even losses (Hugo et al., 2006: 82). Such a business also runs the risk of being excluded from tendering for future business.

The conditions of the modern business world, characterised by globalisation, tough competition, increasingly stringent quality requirements and 
the technological revolution which shortens the life cycle of products, make selecting the right supplier a daunting challenge for purchasing and supply management. To complicate the selection and purchasing process further, a modern global trend is to focus on closer relations, which implies fewer preferred suppliers, longerterm contracts and e-procurement (Leenders, Johnson, Flynn \& Fearon, 2006: 495).

Burt, Dobler and Starling (2003: 84) define a good supplier as one with a stable background; who always supplies the specified quality at a fair and competitive price; and takes the initiative when it comes to technical renewal, technical support, technical expertise and the suggestion of better methods of production and service delivery. Only established suppliers, however, tend to meet these criteria. Disadvantaged and small suppliers throughout the world, both new entrants to or at the fringes of the main markets, experience a combination of the following problems in their efforts to break into the major markets and become partners of established businesses (Hugo et al., 2006: 341):

\section{(i) Poor communication}

Ineffective interpersonal communication is one of the greatest obstacles to the success of small business purchasing programmes. This is particularly problematic if the business is owned by previously disadvantaged individuals, since this often creates problems with language and cultural divides (Hugo et al., 2006: 341). Together with poor communication go expectations that cannot be met, mistrust and prejudice. Small suppliers often accuse buyers of making false promises relating to contracts, loans and technical assistance, while buyers often accuse small suppliers of insisting on being given a contract simply because they are small and belong to previously disadvantaged groups.

\section{(ii) High transaction costs}

For an established business, the cost of tracing, evaluating and developing small suppliers is high in terms of time spent visiting and making telephonic contact, and handling complaints caused by poor quality and/or late deliveries. On the other hand, the small business owner, who is often also the manager and the driving force behind the enterprise, has limited human resource capacity (Grant, Lambert, Stock \& Ellram, 2006: 102). He or she, therefore, has to spend a great deal of time on completing complicated tender documents, negotiating with buyers, learning about the purchasing enterprise's complicated procedures, and developing the technical ability to comply with specifications.

\section{(iii) Satisfaction with current bigger suppliers}

As mentioned above, the global trend is for buyers to deal with fewer preferred suppliers (Leenders et al., 2006: 495). Buyers at established businesses prefer to deal with existing suppliers who have been giving them good service for years, even decades, and with whom they have maintained healthy long-term relations. Furthermore, global sourcing enables established businesses to enjoy the benefits of advanced technological expertise, high-quality standards, lower costs and better service in the form of just-in-time (JIT) delivery.

Given these complex issues with procurement from new and/or small suppliers, it is international practice for buyers to use what is known as a scoring and assessment process, also referred to as a supplier qualification rating or weighted points process, to assist them in their decision to appoint the best possible supplier (Chopra \& Meindl, 2007: 429). In such a process, potential suppliers are rated according to specific evaluation criteria which include:

- quoted price.

- replenishment or lead time.

- timely delivery.

- flexibility and viability.

- delivery frequency or minimum lot size,

- $\quad$ supply or service quality; and

- design collaboration capability.

Each of these listed factors impacts on cost structures in the total supply chain. The importance of each factor is therefore considered and a relative weight allocated to each (for example a score out of 10). The weight of each factor is then multiplied by the rating given for each supplier. A total value or rating for each supplier is obtained this way, which decides who the best supplier is to procure from. 
5

\section{Results of the interviews}

The process of assessing, selecting and appointing a good or the best supplier is not always straightforward in South Africa and is, in most cases, complicated by political pressures. The Broad-Based Black Economic Empowerment Act 53 of 2003, for example, was adopted by the government as a strategy to redress the imbalances in South African society by encouraging and facilitating meaningful participation by previously disadvantaged individuals in the economy (Dekker, 2005). As part of the strategy, industry-specific BEE charters and achievement scorecards are constantly developed and revised for all the key sectors of the economy. Businesses are given empowerment targets to meet in terms of black ownership, management, supplier procurement and skills development, with the main aim eventually of creating a non-racial South Africa (Balshaw \& Goldberg, 2005: 21). Purchasing from small, disadvantaged businesses is regarded as an appropriate tool by which large enterprises can assist in the development of small businesses (Hugo et al., 2006: 335) and support the government's BEE strategy. Pressure is, therefore, put on OEMs in South Africa to procure to a greater extent from BEE suppliers and in this way become actively involved in the socio-economic development of the country.

A complicating factor to be considered, however, is the fact that, by early 2004, all OEMs operating in South Africa were either fully- or majority-owned by parent companies which are situated in foreign countries (Automotive Industry Development Centre, 2005: 7), in which different political and socio-economic conditions prevail. Furthermore, the parent OEMs are mainly interested in maximising their profits and, therefore, assess potential suppliers from any country that tender for contracts, including South Africa, purely in terms of the following four main criteria: quality, supply reliability, technology and price (KPMG, 2004: 3).

Owing to various historical, political and other reasons, BEE and small suppliers in South Africa do not always meet these basic criteria and, therefore, mostly fail to win tenders to supply direct materials, in other words motor vehicle components, to OEMs. This situation is seen as a main reason why the Minister of Trade and Industry announced on 26 October 2004 at the Auto Africa Conference in Johannesburg that the original BEE charter for the automotive industry will not be enforced, but that the industry will be allowed to commit to its own initiatives (Motor industry allowed to BEE, 2004: 17).

It is within this context that we present the findings from the interviews conducted during this project. These findings represent the perspectives of the majority of the respondents on the practical problems experienced by BEE and small suppliers in the Eastern Cape automotive industry:

\section{(i) Lack of finances}

Notwithstanding the fact that more sources of funding are currently available from the government, the private sector and foreign sources than ever before, the majority of the BEE respondents indicate that a lack of the necessary finances is a main factor that limits their chances to tender successfully for contracts and earn a sustainable income. The bulk of the motor vehicles, parts and accessories sector is capital-intensive and technologically advanced, requiring that suppliers have the necessary expensive capital equipment and the latest technology in place. Unfortunately, most BEE suppliers lack the necessary finances to acquire expensive capital equipment and the latest technology, and are thus not in a position to compete internationally. When applying for loans at banks, they also need to produce collateral, which they usually lack.

\section{(ii) Problems with quality and capacity}

Owing to their lack of finances, BEE and small suppliers are often forced to operate on shoestring budgets for their labour, material and capital equipment requirements, which often leads to the production of sub-standard quality and insufficient volumes. Because of the highly competitive environment in which they operate, however, OEMs do not tolerate poor delivery performance or quality risks caused 
by, for example, deviations from specifications or the use of inferior materials. These quality and capacity problems cause production stoppages and delays which require production rescheduling at customer plants. This eventually slows down the entire supply chain and leads to longer lead times, more backorders and lost sales.

OEMs operating in South Africa are part of the Latin American, African and Middle East (LAAM) umbrella standards body and adhere to the same international quality requirements, engineering specifications and purchasing policies for the procurement of their supplies as any OEM anywhere in the world. These standards are continuously evaluated and strictly controlled by means of weekly international telephone conferencing, where members of each OEM's supplier quality and development (SQ \& D) department discuss local supplier pricing and quality, as well as the acceptability thereof.

Day-to-day quality is generally measured in what is called parts per million (ppm). The ppm criteria is calculated as the total number of defective parts delivered divided by the total number of parts delivered, multiplied by 1 million. The industry average is currently between 50 and $200 \mathrm{ppm}$. For a supplier to achieve a $50 \mathrm{ppm}$ benchmark, the reality is that he or she can in effect deliver only 5 defective parts per every 100000 deliveries. This is not easily achieved by new market entrants. A second daily evaluation measure is the number of problems that are reported to the supplier, and a third measure is whether the supplier causes the OEM's production line to stop.

All potential suppliers to OEMs are audited before being awarded a contract. The audit covers aspects such as quality accreditation, production capacity, process capability, design capability, technical agreements, management capacity, staff turnover and joint ventures. Local OEMs send representatives from their supplier quality assurance (SQA) departments and their procurement divisions, including materials management and production control, to the premises of all existing and potential suppliers to evaluate their ability in terms of the abovementioned LAAM quality criteria. All BEE suppliers are similarly audited.
Furthermore, potential suppliers are required to have a system in place to accredit or certify their achievement of a minimum threshold of quality in order for them to tender successfully. The quality standards for the American and German OEMs, e.g. General Motors, Volkswagen and DaimlerChrysler which operate in the Eastern Cape, are sanctioned by the Automotive Industry Action Group (AIAG) and the Verband der Automobilindustrie (VDA) respectively. The quality standards for production-part suppliers are set out in QS 9000 or ISO/TS 16949, and the minimum requirements for warehousing and distribution are described in ISO 9001.

All these thresholds are minimum requirements for placement of business as stipulated by the OEMs. It is clear that BEE suppliers experience difficulties in meeting these stringent standards, especially if they are not supported by a third party in developing capacity. Fortunately, the OEMs have indicated that they do employ supplier development specialists, called supplier quality assurance representatives, who assist suppliers who do not meet the required standards. This assistance takes the form of interim corrective action programmes for the supplier which aims to salvage the situation within a set time schedule. The OEMs then undertake follow-up visits to assess the progress of these suppliers.

In practice, new suppliers who are given a chance to supply parts to an OEM are at first only given contracts to produce low risk production parts. Once better established, and on condition that the OEM is satisfied with their quality and capacity, the suppliers are given higher value contracts and even more critical production parts to produce. Lowrisk or non-critical production parts include, for example, headrests. Cars can go to the stockyard or cripple stockyard until the noncritical parts, in our example the headrests, arrive and the car can be fully completed. Critical parts include engine-mounting brackets, handbrake-cable assemblies and gearboxes. These parts are also known as no-build parts, since no further production can take place if supply is insufficient or if there is a quality problem with these critical parts. 
The daily changing of demand schedules by OEMs also places tremendous pressure on small supply firms who already experience capacity problems. The further back in the supply chain they find themselves, the more exposed they are to erratic call-offs.

\section{(iii) Lack of multi-skills required to source internationally}

These skills include tooling and tool making. When the foreign-based parent company of a South African OEM designs a new model car, that same parent company does the sourcing of each required component on a global basis. Purely on the condition that the parent OEM is satisfied with a component supplier in terms of quality, supply reliability, technology and price, that same supplier is given the contract. The components are designed by means of computer-aided design (CAD) systems that use computer graphics (Stephenson, 2007: 144). Growing numbers of components are designed this way globally as it increases productivity and makes designs and design specifications available much more quickly and cheaply. However, in practice only established suppliers have the supporting infrastructure and computer systems that enable them to design and process the required components and put in tenders. Many BEE and small suppliers have staff who are computer-illiterate, while many of those who are computer literate do not have the finances to afford computers and CAD software. An established supplier in a foreign country which is closer to a parent OEM thus has a major advantage over a potential South African BEE or even established supplier in terms of lead time and distance to the market.

BEE and other suppliers in South Africa are also disadvantaged by the global strategies of assemblers which affect the relationship they have with suppliers in a number of significant ways (Automotive Industry Development Centre, 2005: 4). Firstly, design activities have shifted from assemblers to suppliers, with suppliers moving towards greater customisation and tailoring of their products to the needs of specific assembling companies. The assembler provides the overall performance specifications and information about the interface with the rest of the car, and the supplier, using its own technology, then designs a solution.

Secondly, there is a shift towards the supply of complete functions (namely, systems and subassemblies) rather than individual components. A first-tier supplier thus becomes responsible not only for the assembly of parts into complete units, but also for the management of secondtier suppliers.

Thirdly, the assemblers have become more involved in specifying the production and quality systems of their suppliers. With the increasing importance of JIT production systems and the imposition of quality-at-source controls, even simple tasks have become critical for the overall efficiency of operations. For this reason, assemblers have to invest to a greater extent in their relationship with their suppliers, thereby contributing towards the trend of assemblers having longer-term relationships with fewer suppliers.

This preference by assemblers in many different locations to use the same (few) suppliers is known as follow sourcing. The supplier thus follows the assembler to new locations. This practice is a logical consequence of the supplier taking more responsibility for design and for the increasing commonality of models between markets. Using a follow source ensures that the rest of the supply chain meets the assembler's standards (Automotive Industry Development Centre, 2005: 5), thereby reducing possible risk. This global trend, however, has the potential for OEMs in the country to marginalise local suppliers in preference for trans-national suppliers based in foreign countries, underlining the difficulty for BEE suppliers to win contracts. For example, instead of dealing with a large number of local South African suppliers (including BEE suppliers) whose designs and prototypes have to be homologated (tested and approved for use), and whose production and quality systems have to be audited and improved, the assembler rather deals with a limited number of foreign-based follow source suppliers to provide the required parts or subassemblies at the required standards.

\section{(iv) Lack of opportunities to tender}

It is important to note that OEMs are private companies that cannot easily be forced to give 
BEE suppliers the opportunity to tender, especially if they are satisfied with their current suppliers. Having established comfort zones, OEMs are unwilling to enter into new partnership agreements, especially with new and unknown suppliers. OEMs prefer to simply renew contracts with suppliers they know, with whom they have a satisfactory history, whose products meet their stringent quality standards, and who have a good track record. Only a few lucky new suppliers thus get to know about new tenders and are given the opportunity to tender. If they do get an opportunity to tender, BEE suppliers often have a problem presenting themselves as they lack the necessary experience and confidence.

Two other factors that limit the opportunities of BEE suppliers in South Africa to tender for contracts are global overcapacity and a small domestic market (Automotive Industry Development Centre, 2005: 14). Given the South African automotive industry's export orientation, it enjoys marginal status in relation to an international industry that is rapidly globalising and which has 25-30 per cent excess production capacity. BEE suppliers in South Africa are also limited by the fact that the country does not have the advantage of a major domestic market such as China, Brazil or India, nor is it located adjacent to major markets as is Mexico (in relation to the United States) or Central European countries (in relation to the European Union).

\section{(v) Inability to penetrate into OEMs}

BEE suppliers find it difficult to penetrate into OEMs because as relatively new entrants into the market these suppliers have difficulty obtaining what are known as technical tie-ups with specialised and experienced suppliers, especially those based overseas. Foreign-based specialised gearbox manufacturers, for example, have advanced research and development (R\&D) facilities that assist them in developing their products more extensively. They are also more interested in keeping and expanding their own market share and thereby maximising their own profits than in sharing their expertise and market share with newcomers.

\section{(vi) Lack of management and business skills}

Although many BEE suppliers have the necessary technical skills to produce components, they sometimes lack various management and business skills. Because they operate on a much smaller scale than their established counterparts, these small suppliers do not have the luxury of different departments with skilled personnel responsible for different business functions such as marketing, warehousing, materials handling and packaging. The design staff is often responsible for most of these functions themselves without possessing the necessary skills. Specific skills that are lacking include the following:

- Good management skills: BEE suppliers find it difficult, for example, to delegate tasks, prepare and keep within budgets, and also lack the necessary sales and marketing skills. Skill in planning effectively is often lacking, especially in up-front planning. BEE suppliers are often too hasty and excited to get their products out to the market, causing products to be reproduced or reworked. They also lack the necessary robust planning skills required to optimise their manufacturing methods.

- Logistics skills: BEE suppliers often do not have effective control over materials and ignore the importance of lead times. Furthermore, they experience material flow problems, warehouse problems and inherent wastage as space is not always maximised. This result in the multiple handling of parts and components, as well as high sourcing and storing costs.

- Communication skills: English is in most cases not the mother tongue of BEE suppliers, so they are hampered in their efforts to understand highly technical specifications and contractual clauses. Lack of familiarity with complex business terms may also result in poor communication. As BEE suppliers often accept orders over the telephone, without insisting on hard-copy documentation, incorrect interpretations can lead to confusion, with too little or too much stock ordered and materials either running out or being wasted. 
(vii) Previous lack of opportunities in corporate business

Under the previous dispensation, most previously disadvantaged suppliers were deprived of exposure to and experience in the corporate world. For example, they did not form part of the formal business network that could have aided their development. This means that many of them, under the current dispensation of redress and empowerment, find themselves relatively new to business, and having to concentrate mainly on their internal production processes in order to become better established.

\section{(viii) Unrealistic expectations}

The majority of the respondents in the interviews report that they find the going tougher than they expected. One put it this way, "This game is not for sissies", while another said, "I lived a pipe dream". The BEE suppliers acknowledge that they did not foresee many of the problems outlined above, which now limit their activities severely. The one honestly said, "I definitely lack experience and certain skills" and another, "I have to teach myself many things." Others bluntly state that "It is very difficult to access finance" and "It is very difficult to access contracts from OEMs."

One result of these problems is that BEE suppliers are often only successful in winning tenders for non-production or soft activities. These include mainly the provision of stationery, furniture, security and catering or cleaning services. Another result, which has a more immediate and widespread impact on the South African economy, is a possible increase in the risks and complexities faced by the South African automotive supply chain, as will now be discussed.

\section{6}

\section{Possible risks and complexities as a result of BEE supplier problems}

Logistics and supply chain management deal with intangibles, compared to the tangible products which a producer manages in the physical production environment. To ensure the efficiency and effectiveness vital to competitiveness, and to shorten cycle times, decisions are constantly made in a supply chain. The intangible nature of logistics thus requires that each member of the South African automotive supply chain has full knowledge of how the entire chain functions and realises the importance of his/her contribution towards the chain's overall success. However, because BEE suppliers are relatively new to the corporate world, many do not set up logistical management systems but focus mainly on their internal production. They are therefore prone to the problems explained above. These suppliers often lack a holistic understanding of the automotive supply chain within which they operate. This can lead to the following risks and complexities:

- Slower reaction time of the total supply chain. This happens, for example, when the parts with which the BEE suppliers are entrusted are delivered later than the date specified by the customer's release order, because of the practical problems the suppliers experience or because they do not realise the ripple effect that their late delivery causes further down the total automotive supply chain. Furthermore, multinational OEMs know that, even though BEE suppliers often control only one part, the late or non-delivery of this part can bring the whole supply chain to a complete stop. Such a risk factor could make the South African automotive supply chain less attractive to such multinationals.

- Inventory obsolescence and consequent higher cost caused by engineering changes. Due to the economies of scale principle, which explains that production output is based on minimum quantities, BEE suppliers can end up producing too many of a given part in an effort to minimise their production unit costs. However, when engineering changes specify a change in component levels (in other words new and/or improved parts are required), the already produced parts are no longer required and thus become obsolete. Such waste has cost implications for the supplier. Furthermore, if such a BEE supplier insists that his/her parts be used, there is a risk that the production line of 
the customer firm, and therefore the entire supply chain, could come to a standstill, thus negatively affecting both response time and cost.

- Ultimate consumers paying higher prices and receiving inferior service. As a result of their limited supply chain view and the fact that they do not have a culture of challenging price increase requests initiated by their own supplier base, BEE suppliers often lack ultimate customer affordability information. Furthermore, because of the communication problems discussed above, they are not always customer-orientated, with the result that final consumers can be offered products that do not meet their requested specifications. This can lead to the total rescheduling of production, cancelled sales and eventually higher costs.

These risks could cast doubt on the attractiveness and profitability of the South African automotive supply chain, and will only become more complex and intractable if they are not addressed. Negative factors such as late deliveries, production stoppages, bad service and higher cost structures may cause existing customers and/or potential customers of BEE suppliers to rather source from other suppliers in the same automotive supply chain or even from competitor supply chains.

\section{7}

\section{Policies and programmes in place to assist BEE suppliers}

The South African automotive industry is guided by a common vision "to establish a viable, competitive industry domestically and internationally, capable of achieving both continuous growth and sustainable job creation" (Automotive Industry Development Centre, 2005: 7). The development and upliftment of BEE suppliers, as well as the minimising of possible risks and complications in the South African automotive supply chain, form part of this vision. However, the results of our survey show that BEE suppliers in South Africa are in desperate need of assistance to enable them to become "A-rated" suppliers or at least suppliers to first-tier suppliers. A-rated suppliers are suppliers whose quality, supply reliability, technology and price standards qualify them to become first-tier suppliers to OEMs with the prospect of being awarded continuous business and long-term contracts. BEE and small suppliers need to be assisted to become at least second- and third-tier suppliers who supply components of a safety and critical nature to first-tier suppliers in both South Africa and foreign countries.

Policies and programmes already in place in the South African automotive industry to assist BEE and small suppliers include the following:

\section{(i) The Automotive Industry Development Centre (AIDC)}

BEE and small suppliers in South Africa currently receive major assistance from the Automotive Industry Development Centre (AIDC). The AIDC is a government-supported service provider company that plays a supportive and development role by addressing the needs and objectives of the industry, the government and the wider society as a whole. In 2005, based on its experience in the industry and in consultation with its stakeholders, the AIDC set itself specific institutional objectives, including (AIDC, 2005: 18):

- increasing the contribution of small enterprises to the country's economy;

- increasing broad-based BEE significantly;

- increasing market access opportunities for and export of South African goods and services;

- contributing towards building skills, technology and infrastructure platforms from which enterprises can benefit;

- creating jobs through supplier development programmes, export readiness programmes and the promotion of foreign investment; and

- contributing towards building a single economy that benefits all and bridging the divide between the first and second economies.

The AIDC then restructured its activities to focus its activities towards achieving these goals. 
Currently, therefore, the AIDC's three main focus areas are (AIDC, 2005: 24):

- Supply chain development: Here the aim is to move the automotive industry towards global competitiveness by means of macro logistics projects that are financed by the government. These include strategic infrastructure projects such as airports, ports and supplier parks.

- Supplierdevelopment: Here the aim is to move the enterprise, with the aid of appropriate shop-floor training programmes, towards global competitiveness.

- Skills development and training: Here the aim is to help people achieve global competitiveness by means of appropriate training.

The various training and other programmes which the AIDC offers to small firms and BEE suppliers in partnership with business, government departments and other organisations, including higher education institutions, were outlined earlier in this article in the "Research methodology" section.

\section{(ii) Direct empowerment}

Mechanisms are in place to directly empower BEE and small suppliers. According to government legislation, all suppliers who tender for a contract are evaluated in terms of their executive management responsibility, that is, the percentage of previously disadvantaged individuals (PDIs) in the business who are active decision-takers at middle management, senior management and board level. Only those suppliers who have satisfactory scores can be awarded contracts.

\section{(iii) Indirect empowerment}

Methods of indirect empowerment include preferential procurement and enterprise development. Preferential procurement involves an OEM assessing whether suppliers that tender are truly BEE companies or merely fronting. The share certificates of these companies are inspected to verify and validate their status. All this is followed by on-site visits to inspect the supplier's quality systems, technology, staff composition, social responsibility and spending on enterprise development.

In enterprise development, the formation of joint ventures (JVs) with established white suppliers is strongly encouraged. The following example explains what is meant by a joint venture:

Assume that Business A, which supplies stationery, is owned by "whites", has state-of-the-art technology, is engaged in e-business, is big, well established and is sound financially. Business B, on the other hand, is small, owned by PDIs and operates without the latest technology. Business $\mathrm{B}$, however, is strategically much better situated to serve government contracts in rural areas or negotiate contracts at Bhisho, the provincial capital of the Eastern Cape Province. Business A then buys shares in Business B and ensures that there is a transparent transfer of skills. Business A also ensures that Business $\mathrm{B}$ acquires the latest technology in order to improve its technology capacity, such as e-business and on-line ordering, thereby assisting it to reduce its costs and become more competitive. With Business B now certified as a BEE company with modern technology and being in a JV with a strong business, it has a much better chance of winning state contracts than the white Business A on its own.

The main argument here is thus that both businesses benefit as the two parties share in the profits. According to current law in South Africa, 25.1 per cent is the minimum percentage of shares to be bought in such a JV. This is seen as part of enterprise development where shares are bought in a small business enterprise.

(iv) Human resource $(H R)$ development and employment equity programmes

When an OEM evaluates a supplier that tenders for a contract, factors such as employment equity and equity targets, as well as processes to improve equity targets, are considered. Key questions asked include:

- What sum of money is spent in the business toward human resource development as a percentage of the business's total payroll? 
- What are the employment equity plans of the business? Do these comply with government legislation? What plans are in place to develop PDIs to enable them to participate at middle management, senior management and board level?

\section{(v) Black Business Supplier Development} Programme (BBSDP)

The DTI has instigated the Black Business Supplier Development Programme (BBSDP), which offers financial support to black-owned enterprises in South Africa by way of a 20 percent: 80 per cent cost sharing cash grant incentive scheme (National Association of Automobile Manufacturers of South Africa, 2005). The scheme is designed to assist these firms to improve their core competencies, upgrade their managerial capabilities and become more competitive by means of training. The BBSDP qualification is confined to enterprises:

- that are majority black-owned (50.0 per cent plus one share) and have a significant representation of black managers;

- with a maximum annual turnover of R12 million;

- that have a trading history of at least one year; and

- that comply with regulatory requirements (for example those of the South African Revenue Service).

\section{8 \\ Challenges faced by higher education and other training institutions}

We have mentioned several times that manufacturing and supplier quality assurance follows strict internationally defined standards, and that this implies that local suppliers must be able to design, develop and manufacture complex components that meet OEM specifications if they are to be competitive. Modern trends and the rapid growth in vehicle technology have put severe pressure on all stakeholders to provide the required specific skills in the domestic automotive industry, especially at technical and customer management levels. Only 50.3 per cent of total employment in the sector is currently semi-skilled or unskilled, while 31.4 per cent of the workforce performs jobs that require high-level skills (Automotive Industry Development Centre, 2005: 12). To find workers with the necessary skills has thus become a major challenge for the local automotive industry in its effort to be viable, internationally competitive and capable of achieving continuous growth and sustainable job creation.

This skills challenge exists against a background of a general skill shortage in South Africa (Skills Development Planning Unit, 2005: 31). The legacy of apartheid, particularly the denial of access to quality education to the vast majority of the population, has caused many employees in the automotive industry to lack the basic skills required to meet the challenges posed by the industry's structural transformation. Fortunately, this reality is fully appreciated by the current South African government, which has in recent years committed itself to the Human Resource Development Strategy (HRDS) and the National Skills Development Strategy (NSDS) in order both to be more responsive to the education and training needs of its citizens and also to make South Africa more globally competitive. Furthermore, support organisations, such as the AIDC (both Eastern Cape and Gauteng), are increasingly busy establishing partnerships with the higher education sector to facilitate the implementation of learnerships and are actively involved in various skills development programmes.

The skills shortage together with these various programmes implemented by the AIDC and individual OEMs offer South Africa's higher education sector an opportunity and a challenge. Higher education institutions must form partnerships with the automotive industry, the AIDC and the government to equip the current labour force and new entrants with the specific skills they require.

Unfortunately, many lecturers at universities and Further Education and Training (FET) colleges still suffer from what can be called the "classic textbook syndrome". This means that in the classroom environment students are merely 
told about and not shown what happens in industry. However, it has become necessary for higher education institutions to go to industry and find out how things work in practice. Academics need to be made aware of the fact that they need to teach what industry requires. Speakers from industry should be encouraged to visit the classroom. For these reasons the AIDC introduced the Tertiary Education Industrial (TEI) programme whereby students are assisted to develop capacity and to align themselves with the current trends and requirements of industry. The TEI programme was initiated in Gauteng and then replicated at the Nelson Mandela Metropolitan University and various colleges in Port Elizabeth and the Eastern Cape. The idea of the TEI is to equip facilitators and lecturers to deal with the requirements and needs of industry. In the TEI programme, students work on projects within industry to support their studies and to build their understanding of how industry works in practice. The generic knowledge students acquire at higher education institutions is then complemented by more specialised knowledge they gain from firms in the automotive industry.

This attitude and method of giving students more practical exposure and training assists higher education institutions in addressing two of their main challenges, namely, to ensure that the programmes they offer:

- $\quad$ are relevant, job specific and comply with industry requirements; and

- enable students to become employable and ready for the job market.

\section{9}

\section{Conclusion and recommendations}

If previously disadvantaged and/or BEE suppliers are to successfully tender for contracts, they need to be capable of meeting the stringent global requirements for the quality, supply reliability, technology and price of their products and services. If not, they will limit their competitive edge and ability to win contracts. The South African government prioritises redress, so any lack of competitiveness among previously disadvantaged suppliers can have serious negative consequences for national and international perceptions of the risks and complexities associated with the South African automotive supply chain. The policies and political objectives recommended by the South African government, therefore, need to be synchronised with the programmes and policies currently followed by the AIDC and other private stakeholders involved in the South African automotive industry, if previously disadvantaged suppliers are to share in the successes of the country's automotive industry. These policies and programmes need to create an environment in which BEE suppliers are given sufficient support to enable them to develop, reach their potential and become A-rated suppliers who can supply to OEMs and/or first-tier suppliers both locally and internationally. Higher education institutions also need to ensure that they offer job-specific learning content that enables their students to be appropriately skilled and become employable in the internationally competitive automotive industry.

This project has several limitations. It investigates only a few of the problems experienced by previously disadvantaged suppliers in the Eastern Cape automotive industry. However, since the sample size for the survey was only 30 respondents, the intention is not to make generalisations about the country's automotive industry as a whole, but to offer focused insights into the industry in the Eastern Cape. Also, although training for disadvantaged suppliers and students is offered at various higher education institutions in the country, this article focuses more on the specific training offered by the AIDC in the Eastern Cape Province. However, the findings of the article can be used as a basis to conduct further research on various issues affecting the South African automotive sector.

Note:

The NRF is acknowledged for its financial assistance in this research project.

\section{References}

1 AUTOMOTIVE INDUSTRY DEVELOPMENT CENTRE (2005) Strategy and Business Plan for the 
Automotive Industry Development Centre: AIDC Gauteng and AIDC Eastern Cape, Automotive Industry Development Centre: Pretoria.

2 BALSHAW, T. \& GOLDBERG, J. (2005) Cracking Broad-Based Black Economic Empowerment, Human \& Rosseau: Pretoria.

3 BURT, D.N.; DOBLER, D.W. \& STARLING, S.L. (2003) World Class Supply Management, McGrawHill: New York.

4 CHOPRA, S. \& MEINDL, P. (2007) Supply Chain Management, Pearson Education: Upper Saddle River, NJ.

5 DEKKER, C. (2005) "Business and investment in South Africa". http://www.cliffedekker.co.za/ literature/invest/bee.htm. (Accessed 7 December 2005.)

6 GRANT, D.B.; LAMBERT, D.M.; STOCK, J.R. \& ELLRAM, L.M. (2006) Fundamentals of Logistics Management, McGraw-Hill: London.

7 HUGO, W.M.J.; BADENHORST-WEISS, J.A. \& VAN BILJON, E.H.B. (2004) Supply Chain Management, Van Schaik: Pretoria.

8 HUGO, W.M.J.; BADENHORST-WEISS, J.A. \& VAN BILJON, E.H.B. (2006) Purchasing \& Supply Management ( $5^{\text {th }}$ ed.) Van Schaik: Pretoria.

9 KPMG (2004) Auto Executive Survey. [Compact disk]. KPMG: Pretoria.

10 LEENDERS, M.R.; JOHNSON, P.F.; FLYNN, A.E. \& FEARON, H.E. (2006) Purchasing and
Supply Management (13 ${ }^{\text {th }}$ ed.) McGraw-Hill: New York.

11 THE HERALD (2004) "Motor industry allowed to BEE", The Herald, 28 October, p.17.

12 MAY, J. (2005) "Poverty and inequality report", School of Development Studies, University of KwaZulu-Natal: Durban.

13 NATIONAL ASSOCIATION OF AUTOMOBILE MANUFACTURERS OF SOUTH AFRICA. (2005) "Black business supplier development programme (BBSDP): Incentives available from the Department of Trade and Industry", http:// www.naamsa.co.za/BEE/bbsdp/htm. (Accessed 13 September 2005.)

14 NATIONAL ASSOCIATION OF AUTOMOBILE MANUFACTURERS OF SOUTH AFRICA. (2007) "Industry vehicle sales, exports and imported data", http://www.co.za/naamsa/papers. htm. (Accessed 24 June 2007.)

15 SKILLS DEVELOPMENT PLANNING UNIT. (2005) State of Skills in South Africa, 2005. Department of labour: Pretoria.

16 STEPHENSON, W.J. (2007) Operations Management, McGraw-Hill: New York.

17 VOGT, J.J.; PIENAAR, W.J. \& DE WIT, P.W.C. (2005) Business Logistics Management, Oxford University Press Southern Africa: Cape Town. 